\title{
Additional types of Papilionoidea from the collection of the National Museum of Natural History, Sofia (Lepidoptera)
}

\author{
Stanislav Abadjiev ${ }^{1}$, Mario Langourov ${ }^{2}$
}

\author{
National Museum of Natural History, Bulgarian Academy of Sciences, 1 Tsar Osvoboditel Blvd, 1000 Sofia, Bulgaria, \\ (1)abadjiev@nmnhs.com; https://orcid.org/0000-0001-9106-1754 \\ (2)langourov@nmnhs.com; https://orcid.org/0000-0001-6756-3420
}

\begin{abstract}
The article presents an addition to the catalogue of types of Papilionoidea, kept at the National Museum of Natural History, Bulgarian Academy of Sciences, Sofia and provides data on three nominal species group taxa of Nymphalidae, described from Greece, Kyrgyzstan, and Russia.
\end{abstract}

Keywords: butterflies, Greece, Kyrgyzstan, paratype, Russia, type material

\section{Introduction}

The most recent revision of the collection of Lepidoptera at the National Museum of Natural History at the Bulgarian Academy of Sciences, Sofia (NMNHS) led to the discovery of type material of three nominal species group taxa of butterflies (Papilionoidea) that have never been reported previously. Here we present these as an addition to the already published extensive research (Abadjiev \& Langourov, 2020). The museum is well known as a depository of important collections of mostly Balkan butterflies and moths. Other publications on type materials of Balkan butterflies include those on the collections of the former Institute of Zoology [currently Institute of Biodiversity and Ecosystem Research] at the Bulgarian Academy of Sciences, Sofia (Abadjiev, 2001), Natural History Museum, London (Abadjiev, 2002, 2006), and Laboratoire d'Entomologie, Muséum national d'Histoire naturelle, Paris (Abadjiev, 2018).

\section{List of taxa}

The taxa accounts are arranged alphabetically and each entry includes the associated family name, original combination, type locality, type specimens as specified with their labels, and notes about the type material and current taxonomic status. The text of the label is quoted in double quotation marks and each label is provided with the characteristics of the used paper. Each line in the text of the label is separated by a vertical bar "|".

puella Churkin, 1999 (Nymphalidae)

"Clossiana erda puella subspec. nov." (Churkin, 1999: 121). Type locality: "Russia, Buryatia, Barguzin Mts., Nesterikha River, Kedrovoe Lake, 1900-2000 m" (Fig. 1) (Churkin, 1999: 121).

Paratype $\hat{\sigma}$ (Fig. 2) with labels: (1) printed (on white paper with black frame) "RUSSIA, Buryatiya reg., | Barguzinsky Mts., upper | Nesterikha r., 1200m, | 20.06.1996. leg. V.Tuzov"; (2) printed (on red paper with black frame) "PARATYPE | Clossiana erda | puella | Churkin"; (3) printed (on white paper) "NMNHS-INV-T-01172";

The type series consisted of $87 \hat{\jmath} \widehat{\jmath}, 44$ 우 (Churkin, 1999: 121). Originally described and currently treated as a different subspecies, Boloria (Clossiana) erda puella (Churkin, 1999) (Korb \& Bolshakov 2011: 34), endemic for the Barguzin Range, Buryatia, Russia. 


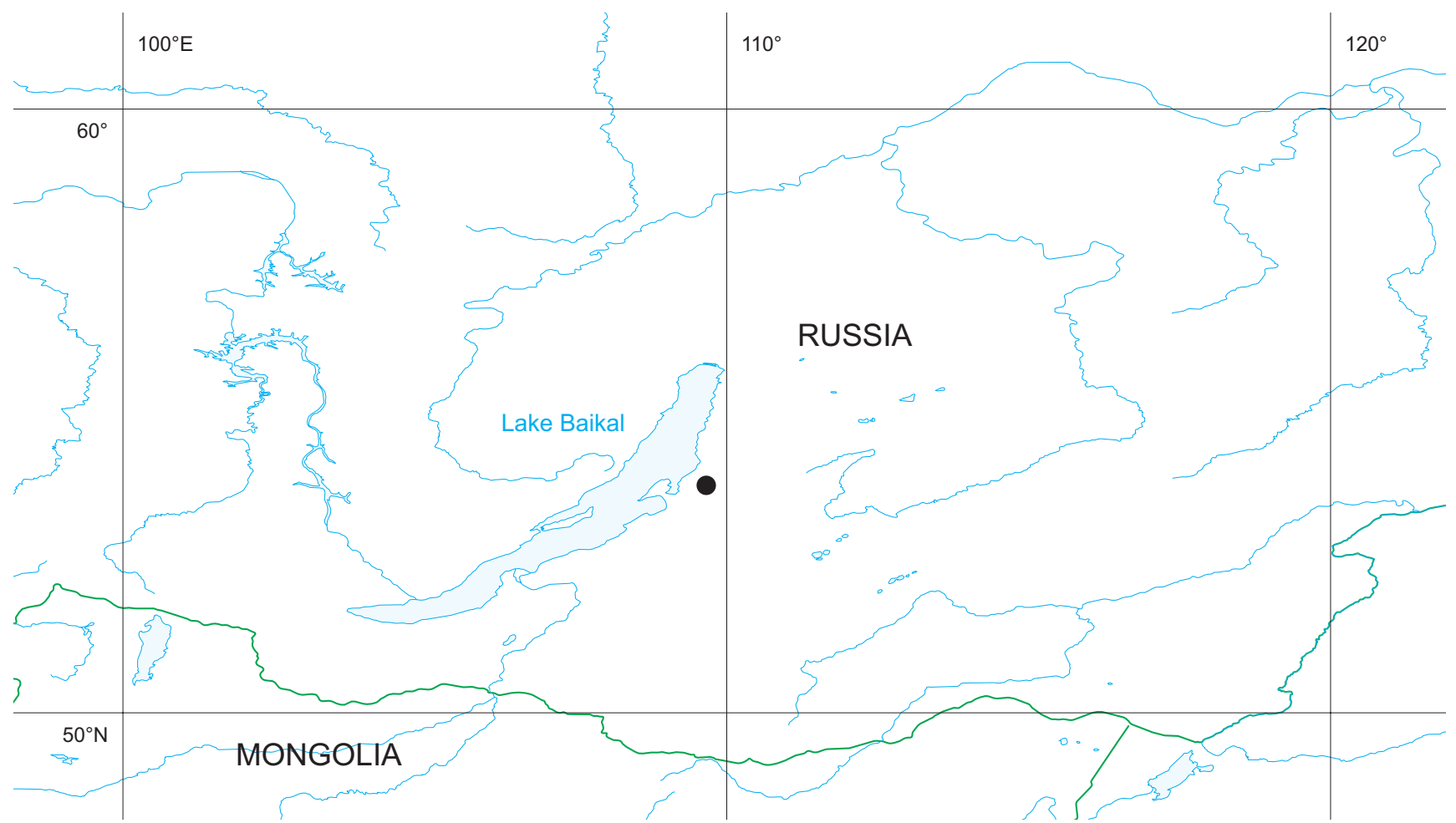

Fig. 1. Map showing the type locality of Boloria erda puella, generated with QGIS 3.2 Bonn, Mac OS X version.

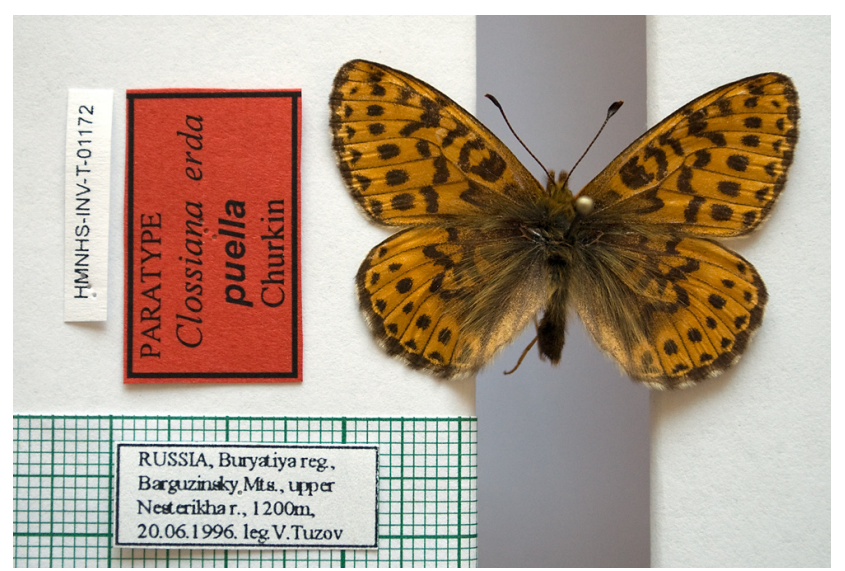

Fig. 2. Boloria erda puella, paratype $\widehat{\jmath}$.

pyramus De Louker \& Dils, 1987 (Nymphalidae)

"Proterebia phegea pyramus n.ssp." (De Louker \& Dils, 1987: 157). Type locality: "Greece, province of Kozani, 600 m” (De Louker \& Dils, 1987: 159).

Paratypes $7 \hat{\partial} \hat{O}, 1$ q with labels: [1 $\hat{\jmath}]$ printed (on white paper) "NMNHS-INV-T-01174"; [2 $\left.\begin{array}{l}2 \\ 0\end{array}\right]$ printed (on white paper) "NMNHS-INV-T-01175"; $\left[\begin{array}{ll}3 & 3\end{array}\right]$ printed (on white paper) "NMNHS-INV-

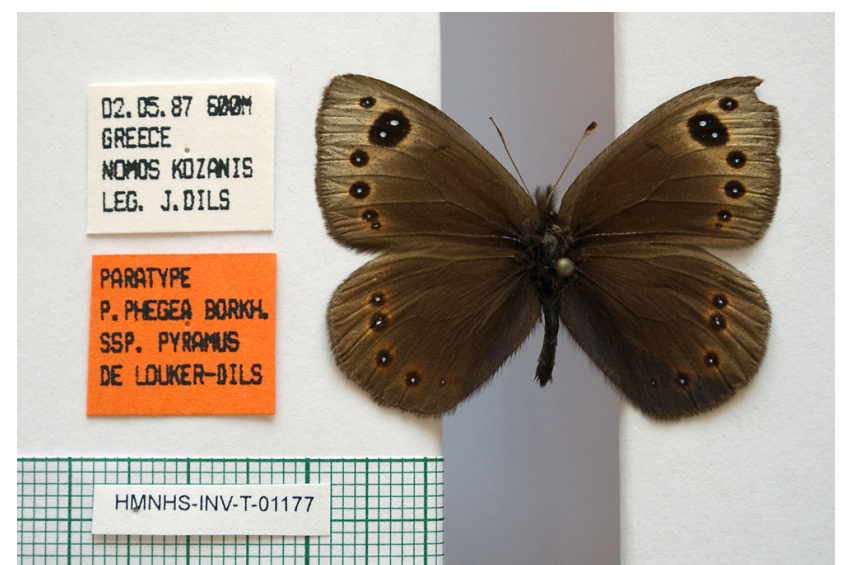

Fig. 3. Proterebia afra pyramus, paratype $\widehat{\jmath}$.

T-01176"; [4 ठ] (Fig. 3) printed (on white paper)

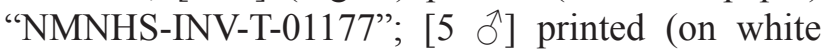
paper) "NMNHS-INV-T-01178"; [6 $\begin{aligned} & 6 \\ & \text { ] }\end{aligned}$ printed (on white paper) "NMNHS-INV-T-01179"; [7 $\left.{ }^{\wedge}\right]$ printed (on white paper) "NMNHS-INV-T-01180"; [ 8 q] printed (on white paper) "NMNHS-INV-T-01181"; all the paratypes with additional, (1) printed (on white paper) "02.05.87 600M | GREECE | NOMOS KOZANIS | LEG. J. DILS”; (2) printed (on red 
Additional types of Papilionoidea from the collection of the National Museum of Natural History, Sofia

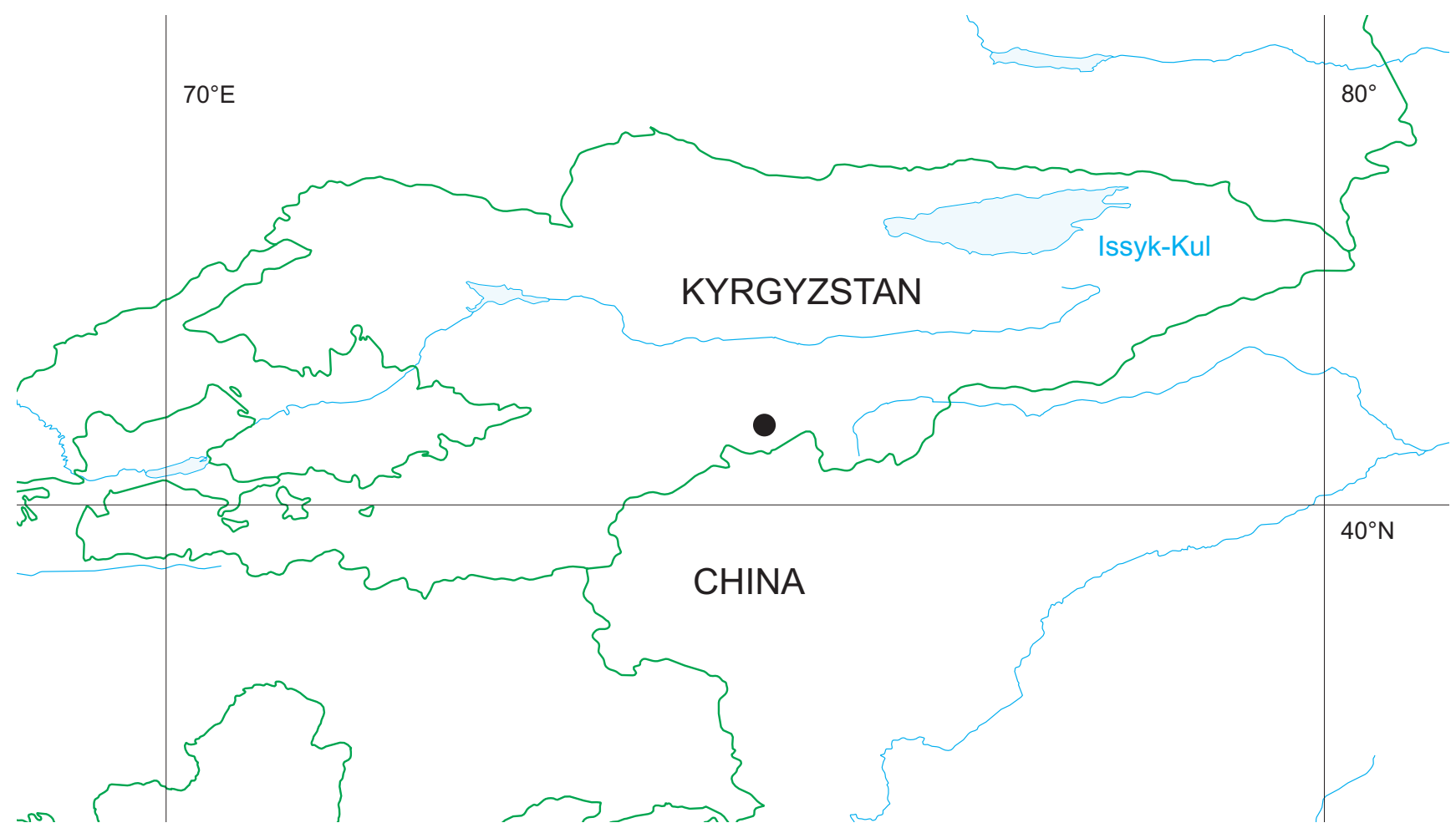

Fig. 4. Map showing the type locality of Erebia radians zhdankoi, generated with QGIS 3.2 Bonn, Mac OS X version.

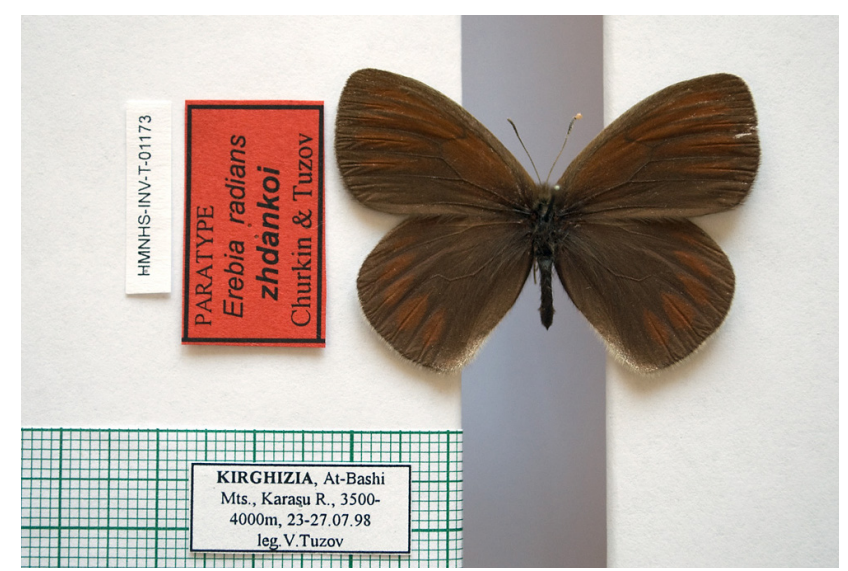

Fig. 5. Erebia radians zhdankoi, paratype $\lesssim$.

paper) "PARATYPE | P. PHEGEA BORKH. | SSP. PYRAMUS | DE LOUKER-DILS”.

Additional types are known from the collections of the Instituut voor Taxonomische Zoölogie, Universiteit van Amsterdam (De Louker \& Dils, 1987: 159) and the Natural History Museum, London (Abadjiev, 2002: 30). Represents as a different subspecies, Proterebia afra pyramus De Louker \& Dils, 1987 (Abadjiev, 2002: 29), endemic for Greece. zhdankoi Churkin \& Tuzov, 2000 (Nymphalidae)

"Erebia radians zhdankoi subspec. nov." (Churkin \& Tuzov, 2000: 92). Type locality: "Inn. Tian-Shan, SW edge of At-Bashi Mountains, near Chatyr-Kel L., Karasu r., 2700-3900 m" (Fig. 4) (Churkin \& Tuzov, 2000: 92).

Paratype $\hat{\sigma}$ (Fig. 5) with labels: (1) printed (on white paper with black frame) "KIRGHIZIA, At-Bashi | Mts., Karasu R., 3500- | 4000m, 23-27.07.98 | leg. V.Tuzov"; (2) printed (on red paper with black frame) "PARATYPE | Erebia radians | zhdankoi | Churkin \& Tuzov"; (3) printed (on white paper) "NMNHS-INVT-01173";

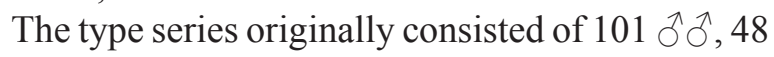
$q q$ (Churkin \& Tuzov, 2000: 92). Treated as a different subspecies, Erebia radians zhdankoi Churkin \& Tuzov, 2000 (Korb \& Bolshakov 2011: 52), endemic for Inner Tian-Shan, Kyrgyzstan.

\section{Acknowledgements}

Financial support for this research was provided through the project "Development of National Cen- 
tre of Excellence in Biodiversity and Ecosystem Research-CEBDER".

\section{References}

Abadjiev S. 2001 An annotated list of type specimens of Lepidoptera deposited in the collection of the Institute of Zoology, Sofia. I. Butterflies (Lep.: Papilionoidea). The Entomologist's Record and Journal of Variation 113: 19-23.

Abadjiev S. 2002 Types of Balkan butterflies in the collection of The Natural History Museum, London (Lepidoptera: Hesperioidea \& Papilionoidea). Neue Entomologische Nachrichten 53: 3-53.

Abadjiev S. 2006 A supplement to "Types of Balkan butterflies in the collection of Natural History Museum, London" (Lepidoptera: Papilionoidea). The Entomologist's Record and Journal of Variation 118: 207-209.

Abadjiev S. 2018 Types of Balkan butterflies in the collection of Muséum national d'Histoire naturelle, Paris (Lepidoptera: Papilionoidea). Historia naturalis bulgarica 33: 1-12. https://doi. org $/ 10.48027 / \mathrm{hnb} .33 .01001$
Abadjiev S., Langourov M. 2020 The type specimens of Papilionoidea in the collection of the National Museum of Natural History, Sofia (Lepidoptera). Zootaxa 4790 (3): 473-490. https://doi. org/10.11646/zootaxa.4790.3.3

Churkin S.V. 1999 New taxa of butterflies from Transbaikalia, Russia (Rhopalocera: Satyridae, Nymphalidae). Atalanta 29 (1/4): 107-124, colour plates VIII, IX.

Churkin S.V., Tuzov V.K. 2000 Revision of the Erebia radians species-group from Tian-Shan and Pamiro-Alai regions (Lepidoptera: Satyridae). Atalanta 31 (1/2): 87-112, colour plates I-III.

De Louker S., Dils J. 1987 The occurrence of Proterebia phegea Borkhausen in Greece with description of a new subspecies (Lepidoptera: Nymphalidae: Satyrinae). Phegea 15 (3): 157-160.

Korb S.K., Bolshakov L.V. 2011 A catalogue of butterflies (Lepidoptera: Papilionoformes) of the former USSR. Second edition, reformatted and updated. Eversmannia supplement 2: 1-123. 